DOI:

\title{
THE INFLUENCE OF LANGUAGE ON THE MEDIATIZATION OF GEORGIAN MASS MEDIA ON EXAMPLE OF GEORGIAN-INDIAN RELATIONSHIP
}

\author{
Valentin Viktorovich Matvienko \\ PhD in Philological Sciences, lecturer \\ RUDN University \\ (Moscow, Russia) \\ e-mail: www.danaramay.ru@mail.ru \\ Kurmanova Danara Baurzhanovna \\ Master of Journalism \\ RUDN University \\ (Moscow, Russia) \\ e-mail: www.danaramay.ru@mail.ru
}

\begin{abstract}
The development of Internet, particularly, social media, allows Georgian Mass Media to transit its model from convergence to multimediatization - from a merger of different informational and communicative processes to digitalization. Surely, multimediatization demands fundamental change of content, transformation of a standard text into the multrimediallondread. Nowadays each newsbreak participates in the construction of mediareality and, in this case, issue on relationship between Georgia and India, which has been widely discussed in the Mass Media since 2017, becomes actual and special.
\end{abstract}

Key words: media, Multimediatization, mediatext, multimediallongread, Georgia, India

\section{ВЛИЯНИЕ ЯЗЫКА НА МЕДИАТИЗАЦИЮ ГРУЗИНСКИХ СМИ (НА ПРИМЕРЕ ГРУЗИНСКО-ИНДИЙСКИХ ОТНОШЕНИЙ)}

\author{
Валентин Викторович Матвиенко \\ кандидат филологических наук \\ Российский университет дружбы народов (РУДН) \\ (Москва, Россия) \\ e-mail: www.danaramay.ru@mail.ru \\ Данара Бауржановна Курманова \\ магистр по специальности «Журналистика», аспирант \\ Российский университет дружбы народов (РУДН) \\ (Москва, Россия) \\ e-mail: www.danaramay.ru@mail.ru
}

\begin{abstract}
Аннотация.Сразвитиеминтернета, вчастности, социальныхсетей, грузинскиеСМИпереходят от этапа конвергенции к мультимедиатизации, то есть от слияния различных информационных и коммуникативных процессов в один ресурс к дальнейшему переходу информации в цифровую форму. Безусловно, мультимедиатизация СМИ предполагает кардинальное изменение контента, преобразование стандартного журналистского текста в мультимедийный лонгрид. Отныне каждый инфоповод участвует в построении медиареальности, и особого внимания в грузинской медиасфере заслуживает, в силу своей малоизученности, вопрос грузинско-индийских отношений, освещаемый в СМИ с 2017 года по сей день.
\end{abstract}

Ключевье слова: медиа, мультимедиатизация, медиатекст, мультимедийный лонгрид, Грузия, Индия

ВВЕДЕНИЕ. Медиапространство Грузии является малоизученным само по себе: после распада Советского Союза обширных исследований грузинской журналистики не проводилось, а Национальное агентство статистики Грузии, возникшее в 1991 году, в 2004 году было упразднено и превращено в один из отделов Министерства экономики и устойчивого развития, в связи с чем отчеты ведомства в сфере журналистики носили краткий и обобщенный характер. Независимость агентство статистики заново обрело лишь в 2010 году (National Statistics Office of Georgia. History of Geostat).

Агентство статистики не предоставляет полноценных отчетов о развитии медиарынка Грузии. Несмотря на то, что данные о выходящих в Грузии СМИ публикуются ежегодно начиная с 2005 года, прежде всего, агентство не включает в их число интернет-СМИ, указывая лишь печатные, а в условиях современного мира такое исследование нельзя считать 100\% точным. Во-вторых, данные за 2018 год до сих пор не опубликованы, последний отчет датируется 2017 годом, однако в нем отсутствует такой важный показатель, как общее количество экземпляров 218 газет и журналов, зарегистрированных в Грузии. (National Statistics Office of Georgia. Issue on Mass Media). В-третьих, агентство статистики до сих пор включает СМИ в раздел «Культура», не рассматривая медиа как экономический объект. 
Для проведения социологического анализа местной медиасреды обычно привлекали международные фонды вроде Transparency.ge, однако те изучали лишь определенный аспект грузинского медиарынка, не охватывая ситуацию целиком. Систематичность и регулярность в данных исследованиях отсутствуют. К примеру, фонд Transparency.ge время от времени публикует отчет «Кому принадлежат медиа Грузии». Последний отчет был опубликован в апреле 2019 года, предыдущий - в начале 2015 года, и, что важно, методы социологического исследования в них отличаются друг от друга, что затрудняет возможность сравнительного анализа.

Отчет за 2015 год делится опросом населения на тему: «Как часто вы пользуетесь интернетом» и сравнивает показатели 2013-го и 2015-го годов, в результате чего становится ясно, что показатель граждан Грузии, пользующихся интернетом каждый день, возрос с 31\% до 35\%.В новом отчете этот опрос отсутствует. Вместо него предоставлены результаты опроса: «Что вы считаете главным и вторичным источником информации?», то есть совершенно другой анализ, который невозможно сравнивать с исследованиями 2013-го и 2015-го годов. По результатам опроса 72\% жителей Грузии выбирают телевидение как главный источник информации, поскольку телевидение охватывает все регионы страны и является бесплатным. Интернет как СМИ выбирают всего 18\% граждан (Transparency.ge. Who Owns Georgian Media?).

Тем не менее даже по имеющимся скудным цифрам можно утверждать, что, если интернет обогнал традиционные печатные СМИ и радио по востребованности и популярности, значит, в Грузии развивается процесс мультимедиатизации СМИ как логическое продолжение медиаконвергенции. В связи с этим уместно назвать журналистику Грузии конвергентной. Ведь, согласно определению Е.В. Олешко, конвергенция СМИ это слияние информационных и коммуникативных процессов в один инфоресурс, продуцирующий общий контент (Oleshko 2015). Рассмотрим примеры конвергентных СМИ Грузии ниже.

АНАЛИЗ КОНВЕРГЕНТНЫХ СМИ ГРУЗИИ. В условиях медиаконвергентности способы передачи информации стали намного разнообразнее благодаря глобализации и диджитализации. Слово, изображение, звукозапись, элементы кинематографа объединяются в один медиапродукт, формируя совершенно новый рынок. Также средства массовой информации переживают тенденцию слияния с крупными компаниями и превращаются в бизнес-объект.

Так, например, медиахолдинг «Имеди», считающийся самым влиятельным в стране, включает в себя телеканалы «Имеди», «Маэстро» и «GDS». Известно, что холдинг принадлежит медиамагнату Инне Гудавадзе, владелице компании «GeorgianMediaProductionGroup». Ей же принадлежат радио «Имеди», кинокомпания «Имеди филмс», компания «Тач медиа», занимающаяся продакшном, медиашкола «Имеди», тбилисский парк Мтацминда. Фильмы, снятые на базе «Имеди филмс», транслируются на каналах, входящих в активы холдинга, на территории парка Мтацминда вещает радиостанция «Имеди ФМ» (Transparency.ge. Who Owns Georgian Media?,4). Всё это позволяет сделать вывод о том, что конвергентные СМИ способны объединить различные типы СМИ в единое целое.

Другой тип конвергенции - это конвергенция услуг, и здесь в качестве примера можно взять ведущего мобильного оператора страны Магтиком, сегодня предлагающего целый спектр услуг в одном онлайн-кабинете: пакет мобильного интернета, домашний интернет, тариф безлимитных звонков на мобильные номера других операторов и стационарные телефоны, кабельное телевидение, - все эти услуги можно приобрести у одного оператора, и, судя по тому, что Магтиком лидирует на грузинском рынке, клиенты явно видят в этой универсальности огромное преимущество. Мультифункциональность сервиса и простота интерфейса делают услуги компании удобнее.

Но что же такое тогда мультимедиатизация? Этот процесс вновь ярко иллюстрирует «Имеди»: в социальных сетях появились аккаунты телеканалов, принадлежащих холдингу, которые с каждым годом приобретают все больше элементов СМИ: соблюдается регулярность публикаций, каждая страница стремится привлечь к себе как можно больше аудитории, делится текстами в различных жанрах для различных рубрик, при этом снабжает их иллюстрациями, взаимодействует с аудиторией, устраивая опросы, проводит прямые эфиры со знаменитостями, то есть производит контент. Мультимедиатизация - переход информации в цифровую форму, то есть ее трансформацию в мультимедийный продукт.

Говоря простым языком, сегодня практически все СМИ обладают онлайн-версией, и, если сравнить эти два варианта, получается, что под одним брендом по сути выходят два различных по жанру и форме медиапродукта. Более того, у издания обязательно будут страницы в социальных сетях, и формат в них тоже будет кардинально отличаться: в Instagram текста меньше, чем в Facebook, Twitter ограничивает нас короткими сообщениями, в YouTube - исключительно видеоконтент и т.д. Версии в соцсетях носят более динамичный и интерактивный характер, чем сайт.

Если раньше в интернете были востребованы издания-клоны, то есть интернет-версии печатных СМИ, просто копирующие их контент, сегодня на медиарынке Грузии преобладают СМИ-гибриды: онлайн-версия берет публикации из аналога, но при этом создает и собственный контент и в принципе функционирует самостоятельно: например, организует собственные акции, конкурсы, мероприятия, взаимодействует с аудиторией и т.п. Появились и независимые онлайн-СМИ, не привязанные к каким-либо другим медиа, существующие лишь в интернете. Как и традиционные СМИ, они обладают штатом редакторов и корреспондентов, но контент отличается от материалов традиционных СМИ: во-первых, издание работает круглосуточно, во-вторых, материалы появляются намного оперативнеe (Lukina). Здесь в качестве примера можно привести ИА «Спутник Грузия». 
Анализируя мультимедиатизацию ИА «Спутник Грузия», важно выделить несколько факторов. Самый важный - это выбор основных площадок вещания. Своей целевой аудиторией, помимо посетителей сайта, ИА «Спутник Грузия» сделал социальную сеть Facebook. Почему? Фонд Transparency.ge в своем исследовании «Кому принадлежат медиа Грузии?» за 2019 год подчеркивает, что большинство интернет-пользователей Грузии выбирает из социальных сетей именно Facebook.

В каждой публикации «Спутника» обычно задействованы все элементы мультимедийного контента: интервью публикуется в виде текста и сопровождается фотографиями, видеороликами и аудиозаписью разговора. Отдельно в ИА «Спутник Грузия» существует рубрика «Интерактив», содержащая элементы геймификации: к примеру, интерактивные тесты в жанре инфотеймента вроде «В каком регионе Грузии вы могли бы жить?». Кроме этого, в «Интерактиве» публикуют инфографики, обобщающие статистические отчеты Национального агентства статистики Грузии, которые были бы интересны обывателю, карикатуры, рейтинги, голосования и опросы. Очевидно микширование различных видов и каналов передачи информации сразу.

Для мультимедиатизации СМИ характерно явление медиаспектакля - инфоповода, длящегося годами и обрастающего новыми деталями. Одним из таких поводов, заслуживающих анализа, является развитие партнерских отношений между Грузией и Индией.

МУЛЬТИМЕДИАТИЗАЦИЯ ГРУЗИНСКО-ИНДИЙСКИХ ОТНОШЕНИЙ. ДиПломатические отношения между Грузией и Индией были установлены 28 сентября 1992 года, но до сих пор находятся на стадии своего развития. В январе 2019 года министерство экономики и устойчивого развития Грузии объявило, что на протяжении двух лет страны проводили обширное экономическое исследование и теперь готовы начать переговоры о свободной торговле (Sputnik Georgia. Georgia and India start negotiations on free trade).

Согласно данным исследования, если в 2017 году торговый оборот между Грузией и Индией составлял 34,1 миллионов долларов, то в 2018 году увеличился более чем на 10 миллионов, превысив 45 миллионов долларов. Индия и Грузия реализуют несколько крупных совместных проектов, среди которых - производство индийских художественных фильмов на территории Грузии по льготной системе «Снимай в Грузии», передача фермерских хозяйств в аренду индийским предпринимателям и программа «Открытое небо», осуществляющая прямое авиасообщение Тбилиси и Батуми с Дели, Мумбаи, Бангалором, Ченнаи и Гоа (Invest in Georgia)

Данные исследования экономических отношений между Грузией и Индией были опубликованы на сайте Министерства экономики и устойчивого развития Грузии ивызвали внимание ведущих изданий Грузии и Индии. В связи с этим интересно проанализировать, как происходит медиатизация грузино-индийских отношений в СМИ, как трансформируется язык медиатекста на примере данного инфоповода, поскольку известно: современная социокультурная реальность создается с помощью информационно-коммуникационных технологий. аудитории на событие зависит от того, как ей это событие преподнесли. Новость о возможности свободной торговли между Грузией и Индией как раз является инструментом построения медиареальности.

Для сравнительного анализа медиатизации грузино-индийских отношений были выбраны ведущие издания Индии и Грузии - газета «TheTimesofIndia» и информационное агентство «Спутник Грузия». Выбор данных изданий объясняется тремя факторами: каждое из СМИ является самым популярным в своей стране, публикует контент на международных языках, а также представлено в онлайн-формате, то есть доступно не только локальной, но и зарубежной аудитории. В рамках подготовки данной статьи был проведен контентанализ двух изданий, в ходе которого были изучены 30 материалов «TheTimesofIndia» и 43 материала ИА «Спутник Грузия».

Исходя из возникновения устойчивых ассоциаций с определенным географическим местом, можно утверждать: медиареальности свойственно создание медийных образов, иногда стереотипных, то есть для современных СМИ характерно появление «слов-маркеров». «TheTimesofIndia» в своих публикациях о Грузии делает упор на туризм, кухню и религию: об этом упоминается в 14 статьях из 30.

Наиболее часто встречающимся ключевым словом на тему грузино-индийских отношений стало слово «фильм» - «Спутник Грузия» употребляет его в 18,6\% публикаций, а «TheTimesofIndia» - в 20\%. Дело в том, что с 2016 года министерство культуры Грузии запустило программу развития отечественной киноиндустрии «Снимай в Грузии». Данная программа поощряет съемки зарубежных фильмов на территории Грузии и возмещает кинопроизводителям до 25\% потраченной сумы по принципу cash-rebate. По состоянию на май 2018 года в рамках программы было отснято 15 художественных фильмов, что обеспечило грузинской экономике доход в сумме 26 миллионов лари и создание 2 тысяч временных рабочих мест (Film in Georgia. Official Site of the program)

Сотрудничество Индии и Грузии в сфере кинематографа могло бы стать темой отдельного исследования, однако мы сталкиваемся с проблемой дефицита информации - сайт Грузинского национального центра кинематографии предоставляет отчеты лишь до 2009 года включительно, на сайте программы «Снимай в Грузии» нет никаких аналитических данных. Отдельные цифры можно взять только благодаря рубрике «Снимай в Грузии», которую с 2017 года запустило «Спутник-Грузия», но так как формат секции является развлекательным, основной акцент делается на актерский состав, а не на отчетность, поэтому цифр приводится мало. «TheTimesofIndia» рассказывает о сотрудничестве индийского кино с грузинским в аналогичном разделе «Развлечения» и цифрами не делится вообще. В связи с этим провести экономический анализ проекта «Снимай в Грузии» становится невозможным. Если печатный лонгрид обычно включал в себя цифры, мультимедийный лонгрид часто обходится без аналитики в силу сжатости текста из-за обилия жанровых элементов: каждая 
новость об отношениях между Грузией и Индией включала в себя также аудиозапись из интервью, сжатый видеопересказ новостей, иллюстрации.

Помимо слов-маркеров, появляется другой обязательный фактор - имена героев, потому интересны и главные герои новостей. «TheTimesofIndia» в публикациях, посвященных грузино-индийским отношениям, обычнонеоперирует именами: имя экс-президента Грузии Георгия Маргвелашвили фигурировало лишь в одной статье из 30, имя действующего президента Саломе Зурабишвили не упоминается нигде (The Times of India. News about Georgia). Зато «Спутник Грузия» уделяет большое внимание персонификации медиатекста. 16 из 43 материалов рассказывают о гражданах Индии - 6 статей с упоминанием индийских знаменитостей и 6 статей с упоминанием имен предпринимателей, инвестирующих в Грузию. Также «Спутник Грузия» за период с 2016 по 2019 гг. в рамках проекта «Грузия глазами иностранца» опубликовал три интервью с обычными гражданами Индии, переехавшими в Грузию (Sputnik Georgia. Student from India Told What Was Good and Bad in Georgia).

ЗАКЛЮЧЕНИЕ.Очевидно, что прозрачность ведомств, открытая публикация отчетов, информированность населения о деятельности международных индийских компаний в Грузии значительно помогли бы в формировании образов и смыслов, связанных с грузино-индийским сотрудничеством. Медиатизация политических и экономических процессов требует тесного взаимодействия органов власти и СМИ, так как полный анализ сотрудничества Индии и Грузии в сфере медиа помог бы выявить тенденции и перспективы развития грузинского медиарынка.

\section{LIST OF REFERENCES}

Invest in Georgia. Official Site. http://www.investingeorgia.org/ru/keysectors/success-stories

Lukina M. Mass Media of Runet.

http://www.mediascope.ru/ index.php?option=com content\&task=view\&id=59\&Itemid=46

National Statistics Office of Georgia. History of Geostat: https:/www.geostat.ge/index.php/ka

National Statistics Office of Georgia. Issue on Mass Media:

https://www.geostat.ge/en/modules/categories/194/culture

E.V. Oleshko. Convergent journalism: professional culture of subjects of informational activity.2015. - 128 p.

Film in Georgia. Official Site of the program: filmingeorgia.ge

Sputnik Georgia. Georgia and India start negotiations on free trade:

https://sputnik-georgia.ru/economy/20190112/243859420/Gruziya-i-Indiya-nachnut-peregovory-o-svobodnoy-torgovle.html

Sputnik Georgia. Student from India Told What Was Good and Bad in Georgia. https://sputnikgeorgia.ru/reviews/20170925/237373764/Student-iz-Indii-rasskazal-chto-horosho-i-ploho-v-Gruzii.html

The Times of India. News about Georgia: https://timesofindia.indiatimes.com/topic/Georgia

Transparency.ge. Who Owns Georgian Media?-2019»:

https://www.transparency.ge/sites/default/files/media mplobeloba-e.pdf

\section{СПИСОК ЛИТЕРАТУРЫ:}

«Инвестируй в Грузию». Сайт программы:

http://www.investingeorgia.org/ru/keysectors/success-stories

ЛукинаМ.М. СМИРунета:

http://www.mediascope.ru/ index.php?option=com_content\&task=view\&id=59\&Itemid=46

Национальное агентство статистики Грузии. История национального агентства статистики Грузии: https://www.geostat.ge/index.php/ka

Национальное агентство статистики Грузии. Отчет по СМИ: https://www.geostat.ge/en/modules/categories/194/culture

Е.В. Олешко. Конвергентная журналистика : Профессиональная культура субъектов информационной деятельности : [учеб. пособие] / Изд-во Урал. ун-та, 2015. - 128 с.

«Снимай в Грузии». Сайт программы: filmingeorgia.ge

Спутник - Грузия. Грузия и Индия начинают переговоры о свободной торговле: https:/sputnikgeorgia.ru/economy/20190112/243859420/Gruziya-i-Indiya-nachnut-peregovory-o-svobodnoy-torgovle.html

Спутник - Грузия. Студент из Индии рассказал, что хорошо и плохо в Грузии. https://sputnikgeorgia.ru/reviews/20170925/237373764/Student-iz-Indii-rasskazal-chto-horosho-i-ploho-v-Gruzii.html

The Times of India. News about Georgia: https://timesofindia.indiatimes.com/topic/Georgia

Transparency.ge. $\quad$ Исследование «Кому принадлежат гедиа

https://www.transparency.ge/sites/default/files/media_mplobeloba-e.pdf

\section{For citation:}

Matvienko, V.V. \& Kurmanova, D.B. (2019) NEW IDEOLOGEM IN THE DISCOURSE OF AMERICAN MEDIA. International Scientific-Pedagogical Organization of Philologists “WEST-EAST” (ISPOP). Scientific Journal WEST-EAST. Vol 1/1 N1 (October, 2019). pp. 92-96. doi:

\section{Для цитирования:}

Матвиенко, В.В., Курманова, Д.Б. (2019) НОВОИДЕОЛОГЕМА В ДИСКУРСЕ АМЕРИКАНСКИХ СМИ // International Scientific-Pedagogical Organization of Philologists "WEST-EAST" (ISPOP) . Scientific Journal WEST-EAST. Vol 1/1 N1 (October, 2019). C. 92-96. doi: 
Information about the authors: Matvienko Valentin Viktorovich - $\mathrm{PhD}$ in Philological Sciences, lecturer of RUDN University, Moscow, Russia.

Kurmanova Danara Baurzhanovna - Master of Journalism, RUDN University, Moscow, Russia.

e-mail: www.danaramay.ru@mail.ru

Сведения об авторах: Матвиенко Валентин Викторович - кандидат филологических наук, преподаватель РУДН, Москва, Россия.

Курманова Данара Бауржановна - магистр журналистики, аспирант РУДН, Москва, Россия.

e-mail: www.danaramay.ru@mail.ru

Manuscript received: 06/02/2019 Accepted for publication: 09/23/2019

DOI:

\title{
SPECIFICITY OF POLYCODE RADIO DISCOURSE OF THE XXI CENTURY
}

\author{
Natalia Nesterova \\ Doctor of Philology Sciences, Professor \\ Tomsk State University \\ (Tomsk, Russia) \\ e-mail: nesterovatomsk@mail.ru
}

\begin{abstract}
The object of discussion in the article is the radio text functioning in the conditions of modern communication technologies, the subject is the identification of the specificity of the radio text poly-code. Integration processes in the media are regarded as the basis for the development of polycodularity of the studied media discourse's variety. A new approach to radio discourse and its basic unit - radio text - is proposed, which includes the study of radio text as hypertext. The site of the radio station containing content designed for all forms of reception: audio (live recording), audio-visual (video broadcast), visual (transcripts, pages on the social network, comments of listeners, etc.). Radio discourse, represented by means of different semiotic systems, is analyzed as a polycode. The peculiarities of polycodularity of a modern radio discourse are revealed through the levels of polycodularity, distinguished by the way of presentation and perception by the addressee.
\end{abstract}

Key words: radio text, hyperradiotext, polycodularity, radio station site, new text

\section{СПЕЦИФИКА ПОЛИКОДОВОСТИ РАДИОДИСКУРСА ХХІ ВЕКА}

*Исследование выполняется при финансовой поддержке РФФИ, грант № 17-29-09132 «"Новая грамотность" в новых текстах средств массовой коммуникации».

\author{
Наталья Нестерова \\ Доктор филологических наук, профессор \\ Томский государственный университет \\ (Томск, Россия) \\ e-mail: nesterovatomsk@mail.ru
}

\begin{abstract}
Аннотация. Объектом обсуждения в статье является радиотекст, функционирующий в условиях современных коммуникационных технологий, предметом - выявление специфики поликодовостирадиотекста. В качестве оснований для развития поликодовости изучаемой разновидности медиадискурса расцениваются интеграционные процессы в СМИ. Предлагается новый подход к радиодискурсу и его базовой единице радиотексту -, предусматривающий исследование радиотекста как гипертекста. В качестве организационнокоммуникативного центра рассматриваемой разновидности медиадискурса обосновывается сайт радиостанции, содержащий контент, рассчитанный на все формы рецепции: аудиальной (записи эфира), аудиально-визуальной (видеотрансляции), визуальной (стенограммы, страницы в социальной сети, комментарии слушателей и др.). Радиодискурс, репрезентированный средствами разных семиотических систем, анализируется как поликодовый.Выявляются особенности поликодовостисовременногорадиодискурса через
\end{abstract} уровниполикодовости, выделяемые с учётом способа представления и восприятия адресатом.

Ключевые слова: радиотекст, гиперрадиотекст, поликодовость, сайт радиостанции, новый текст 